This item was submitted to Loughborough's Research Repository by the author.

Items in Figshare are protected by copyright, with all rights reserved, unless otherwise indicated.

\title{
Design and operation influences regarding rise and fall time of a photoconductive microwave switch
}

PLEASE CITE THE PUBLISHED VERSION

http://dx.doi.org/10.1109/LAPC.2013.6711871

\section{PUBLISHER}

(C) IEEE

\section{VERSION}

AM (Accepted Manuscript)

\section{PUBLISHER STATEMENT}

This work is made available according to the conditions of the Creative Commons Attribution-NonCommercialNoDerivatives 4.0 International (CC BY-NC-ND 4.0) licence. Full details of this licence are available at: https://creativecommons.org/licenses/by-nc-nd/4.0/

\section{LICENCE}

CC BY-NC-ND 4.0

\section{REPOSITORY RECORD}

Kowalczuk, Emma K., C.J. Panagamuwa, and R.D. Seager. 2019. "Design and Operation Influences Regarding Rise and Fall Time of a Photoconductive Microwave Switch". figshare. https://hdl.handle.net/2134/15819. 


\title{
Design and Operation Influences Regarding Rise and Fall Time of a Photoconductive Microwave Switch
}

\author{
Emma K. Kowalczuk, Chinthana J. Panagamuwa and Rob D. Seager \\ Wireless Communications Research Group \\ School of Electronic, Electrical and Systems Engineering, Loughborough University \\ Loughborough, Leicestershire, U.K.
}

\begin{abstract}
This paper evaluates the effect switch design and control method have on the rise and fall time of a photoconductive microwave switch at $2 \mathrm{GHz}$. The effects of switch dimensions, switch fabrication methods and light intensity of the control mechanism are investigated. Switch rise time is affected by switch dimension and optical illumination intensity. Switch fall time is dependent on passivation of the silicon - which is a fabrication step often used to improve the conductivity within photoconductive devices.
\end{abstract}

Index Terms-photonductive switch, optical control, silicon, switching speed, reconfigurable antenna

\section{INTRODUCTION}

Optically controlled antennas and circuitry are an appealing option when considering design of reconfigurable RF systems [1][2]. Optical control via a fibre optic cable does not require metallic biasing lines on the plane of the antenna in contrast to PIN diodes and MEMS switches. Metallic biasing lines affect the performance of the antenna in a difficult to predict manner.

The RF transmission and linearity of optically controlled switches have been demonstrated previously [3][4]. This study aims to evaluate the effect switch design and control conditions have on rise and fall time of the photoconductive switch. Better understanding in this area will allow the antenna designer to choose an appropriate photoconductive switch optimised for the characteristic of interest e.g. short switching time or low insertion loss. There are a number of different parameters which affect the rise and fall time of a photoconductive switch:

- Light intensity and wavelength of the illumination source

- Switch geometry

- Contact type - capacitive, schottky or ohmic

- Silicon treatment - doping and passivation

Karabegovic et al. [5] report on the impact of semiconductor dimensions and light intensity of the control illumination source on switching time for a GaAs switch used to generate $10 \mathrm{GHz}$ microwave signal. The width of the switch in this case dictates OFF switching speed as the electrons are swept out of the GaAs as opposed to allowing recombination to occur.
Flemish et al. investigate the effect that contact type has on both transmission performance and switching speeds for an optically controlled attenuator [6]. A pulsed LED was used to control the switch, which is fabricated on silicon substrate. In this case, ohmic contacts produced faster switching time of $8-14 \mu \mathrm{s}$, however insertion loss and isolation were degraded when compared to capacitively coupled contacts. In this case, a minimum turn $\mathrm{ON}$ time of $\sim 65 \mu \mathrm{s}$ was observed.

Tawk et al. discuss switching speeds for a phosphorous doped un-passivated silicon switch for use in cognitive radio [7]. Switching times in the region of $8-20 \mu$ s are demonstrated at $8.4 \mathrm{GHz}$ under $50 \mathrm{~mW}$ of illumination. The corresponding difference in return loss between ON and OFF state is $10 \mathrm{~dB}$. These switching speeds illustrate that photoconductive switches are a candidate for use in cognitive radio applications.

In this study, the photoconductive switches consist of a die of lightly doped silicon, attached between two lengths of copper microstrip line, Fig. 1. When illuminated by light of a wavelength of $850 \mathrm{~nm}$, electrons in the silicon become promoted from the valence band to the conduction band and electron-hole pairs are created hence making the silicon conductive. The switch is in its ON state when illuminated which allows the RF signal to propagate through the silicon die.

Different applications may require different levels of

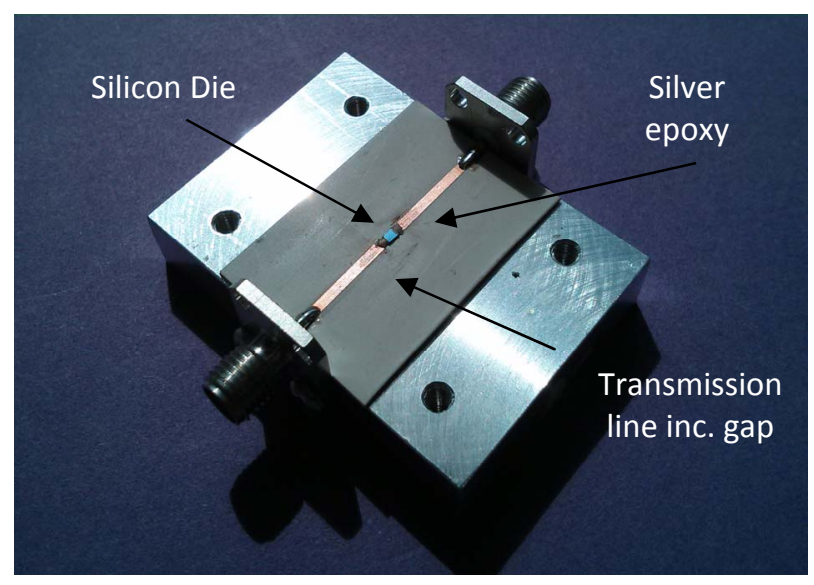

Fig. 1. Photoconductive microwave switch consisting of a die mounted over a gap in transmission line 
isolation and acceptable insertion loss. It is expected the amplitude of the transmitted signal in the ON and OFF states (herein referred to as the ON-OFF voltage) will have an effect on rise and fall times of the switch. The primary aim of this paper is to discuss the effects illumination intensity, geometry and fabrication techniques have on rise and fall times. However consideration is also given to the effect that these criteria have on the ON-OFF voltage ratio, which also has a bearing on switching times. For a photoconductive switch this ratio is easily adjustable.

The time taken to switch on is dependent on how fast electrons are promoted to the valence band. Since silicon is an indirect bandgap material this is dictated by the energy from incoming photons and the presence of phonons. After a certain period of illumination, steady state conductivity is reached within the silicon, which is dependent on size of the silicon die and the rate of recombination due to trap density.

There are two main mechanisms controlling the time taken to switch off a photoconductive switch, recombination time of the carriers and sweep-out time due to electric field. Recombination is dependent on the carrier lifetime of the silicon which is affected by silicon quality and the Auger recombination effect at high injection of carriers. Sweep out time is dependent on the length of the semiconductor that the carriers must traverse through and the mobility of the carrier which is affected by carrier concentration.

\section{EXPERIMENTAL SETUP}

Three types of silicon are presented in this work to investigate the effect doping and passivation has on rise and fall time of the switch. Each silicon die is mounted over varying gap widths using silver epoxy. The different switches along with illumination intensity are presented in Table I.

The substrate is Rogers $3003, \varepsilon_{\mathrm{r}}=3$, thickness $=0.53 \mathrm{~mm}$. The transmission line is designed to be matched to $50 \Omega$. An OSRAM near-IR LED [8] with a centre wavelength of $850 \mathrm{~nm}$ is used to illuminate the die. The LED is pulsed with a 50:50 duty cycle at a frequency of $10 \mathrm{kHz}$ to promote conductivity within the die. Two different light intensities, $55 \mathrm{~mW}$ and $80 \mathrm{~mW}$ are studied.

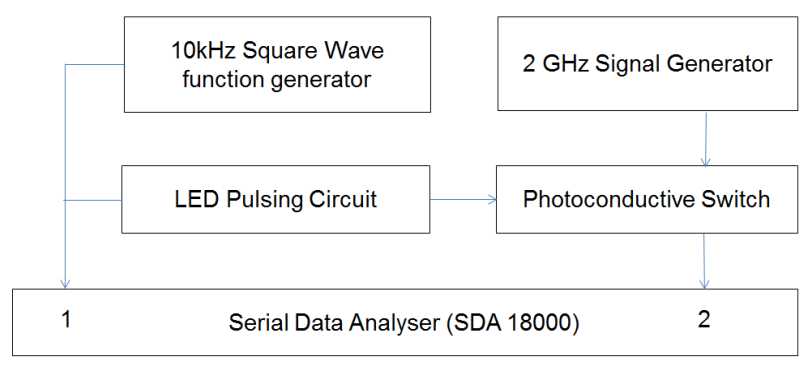

Fig. 2. Experimental setup for measuring the rise and fall time of the photoconductive switch

The light intensity is measured using an optical power meter. Optimum coupling between light source and die is not the focus of this paper, so the assumption is made that the same majority of light is coupled into the die for both the illumination intensities.

Rise and fall time is measured using a LeCroy Serial Data Analyser, SDA 18000, displaying both the triggering pulse and $2 \mathrm{GHz}$ signal envelope of the switch response. The experimental setup is detailed in Fig. 2. The rise time is defined as the time taken for the transmitted RF signal amplitude to change from $10 \%$ of its final value to $90 \%$ of its final value. The fall time is measured in a similar way but in reverse.

\section{S-PARAMETER PERFORMANCE}

For typical S-parameter performance of these silicon switches, the reader is referred to [3] and [9] where data is presented in terms of a constant illumination using a $980 \mathrm{~nm}$ laser diode. For the present study, measured S21 results for Switch A and B under pulsed LED operation are presented in Fig. 3. Both these switches have identical dimensions, doping and gaps in the transmission lines; only the optical illumination intensity is changed.

In the case of Switch A, using an illumination intensity of $55 \mathrm{~mW}$, the $\mathrm{S} 21$ at $2 \mathrm{GHz}$ is $-2.8 \mathrm{~dB}$. The corresponding $\mathrm{S} 11$ at $2 \mathrm{GHz}$ is $-11.6 \mathrm{~dB}$. With regards to Switch $\mathrm{B}$ where an

TABLE I

TYPES OF SILICON SWITCH AND EXPERIMENTAL SETUP. VARIATION INCLUDES CARRIER LIFETIME OF THE SILICON, GAP BETWEEN THE TRANSMISSION LINE, ILLUMINATION INTENSITY AND ON AND OFF STATE VOLTAGE FOR AN INPUT SIGNAL OF $2 \mathrm{GHZ.}$

\begin{tabular}{|c|c|c|c|c|c|}
\hline $\begin{array}{l}\text { Switch } \\
\text { Name }\end{array}$ & $\begin{array}{l}\text { Silicon dimension } \\
(\mathrm{mm})\end{array}$ & $\begin{array}{l}\text { Doping type } \\
\text { (Resistivity) }\end{array}$ & $\begin{array}{l}\text { Silicon Passivation - } \\
\text { carrier lifetime }(\mu \mathrm{s})\end{array}$ & $\begin{array}{l}\text { Gap between } \\
\text { lines (mm) }\end{array}$ & $\begin{array}{l}\text { Illumination } \\
\text { Intensity }(\mathrm{mW})\end{array}$ \\
\hline A & $1 \times 1 \times 0.3$ & $\begin{array}{l}\text { Phosphorous } \\
(10000 \Omega / \mathrm{m})\end{array}$ & 600 & 0.27 & 55 \\
\hline B & $1 \times 1 \times 0.3$ & $\begin{array}{l}\text { Phosphorous } \\
(10000 \Omega / \mathrm{m})\end{array}$ & 600 & 0.27 & 80 \\
\hline $\mathrm{C}$ & $1 \times 1 \times 0.3$ & $\begin{array}{l}\text { Phosphorous } \\
(10000 \Omega / \mathrm{m})\end{array}$ & 600 & 1 & 55 \\
\hline D & $1 \times 1 \times 0.3$ & $\begin{array}{l}\text { Phosphorous } \\
(10000 \Omega / \mathrm{m})\end{array}$ & 600 & 1 & 80 \\
\hline E & $1 \times 1 \times 0.53$ & $\begin{array}{c}\text { Boron } \\
(10000 \Omega / \mathrm{m})\end{array}$ & 36 & 0.27 & 80 \\
\hline $\mathrm{F}$ & $1 \times 1 \times 0.53$ & $\begin{array}{c}\text { Boron } \\
(10000 \Omega / \mathrm{m})\end{array}$ & 14 & 0.27 & 80 \\
\hline
\end{tabular}




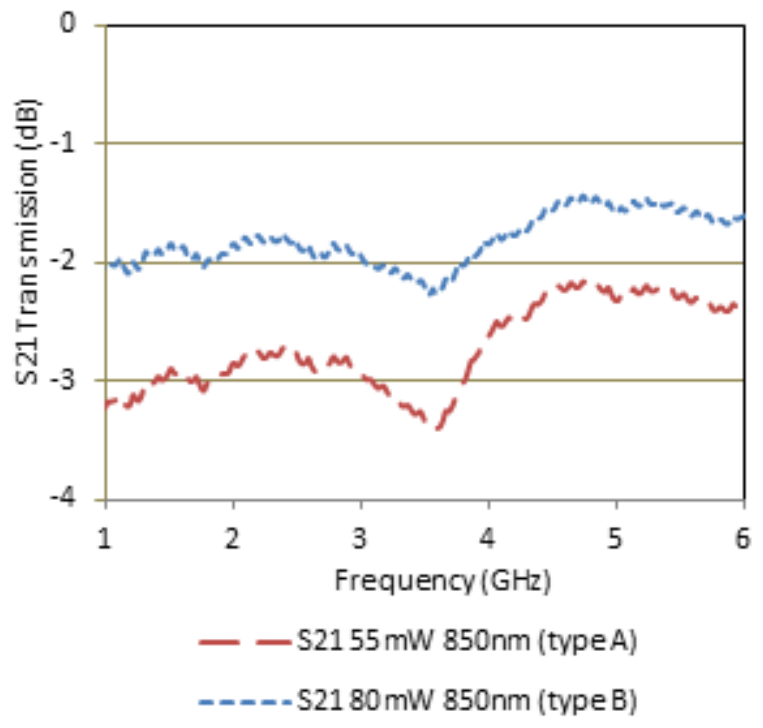

Fig. 3. S-parameter performance for type A and B switch (ON state)

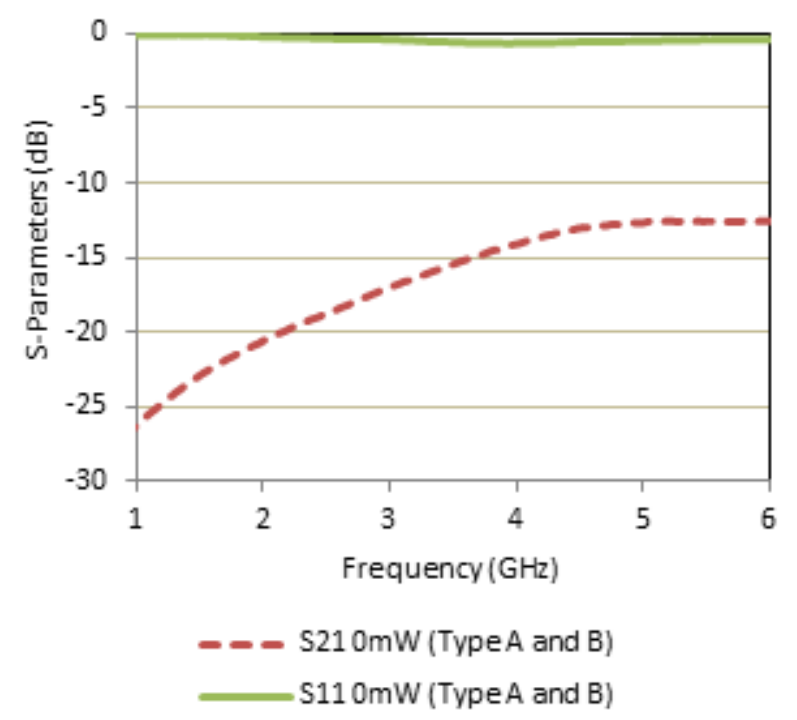

Fig. 4. S-parameter performance for type A and B switch (OFF state, $0 \mathrm{~mW}$ of illumination intensity)

increased illumination intensity of $80 \mathrm{~mW}$ is used, the $\mathrm{S} 21$ in the $\mathrm{ON}$ state is improved to $-1.8 \mathrm{~dB}$. $\mathrm{S} 11$ in this instance is $14.8 \mathrm{~dB}$. For both cases, the corresponding OFF state S21 is $18 \mathrm{~dB}$, and $\mathrm{S} 11$ is $-0.19 \mathrm{~dB}$ at $2 \mathrm{GHz}$, Fig. 4.

\section{RESULTS}

Rise and fall times were calculated for the six variations in silicon passivation quality, switch geometry and varying illumination intensities. The switching graphs for Switch A are presented in Fig. 5 and 6 , which correlate to the Sparameter results presented in Fig. 3 and 4. In this case, rise time is measured to be $17 \mu \mathrm{s}$ and fall time is measured to be $76 \mu$ s. Further analysis of the other switches follows.

\section{A. Switch dimensions and optical power}

Optical light intensity dictates the rate at which photons are injected into the silicon and has a direct effect on the

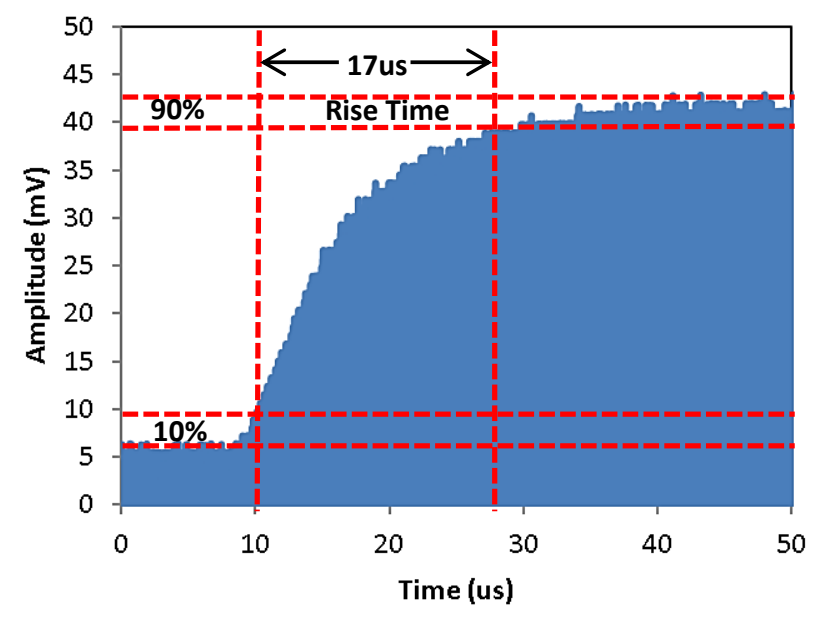

ON-OFF amplitude for a $2 \mathrm{GHz}$ signal passing through silicon type $A(0.27 \mathrm{~mm}$ gap, illumination $55 \mathrm{~mW})$

Fig. 5. Rise time for switch type A, $2 \mathrm{GHz}$

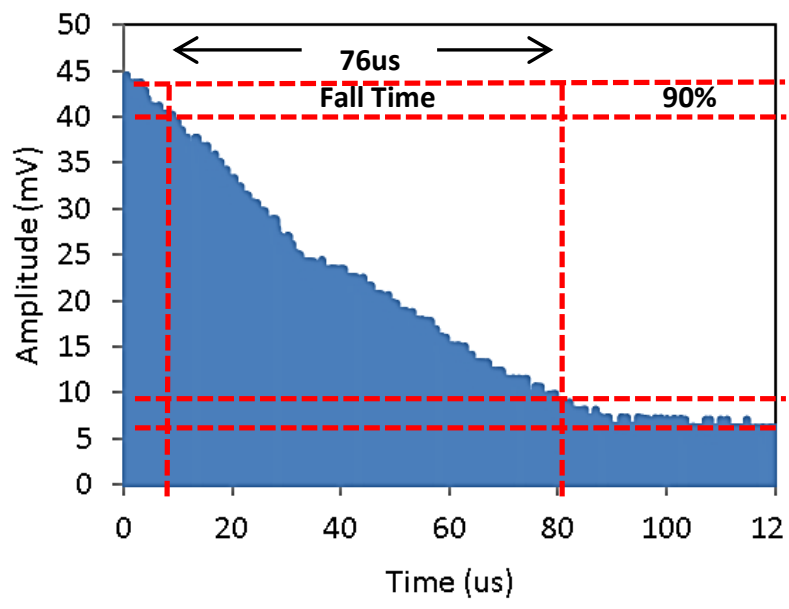

ON-OFF amplitude for a $2 \mathrm{GHz}$ signal passing through silicon type A $(0.27 \mathrm{~mm}$ gap, illumination $55 \mathrm{~mW})$

Fig. 6. Fall time for switch type A, $2 \mathrm{GHz}$

number of free carriers generated in the silicon. Along with switch width, optical light intensity controls the $\mathrm{ON}$ impedance of the switch. In this section switches A, B, C and $\mathrm{D}$ are investigated.

As shown in Fig. 7, for the case of the $0.27 \mathrm{~mm}$ gap geometry, when the $55 \mathrm{~mW}$ light intensity is used (Switch A) a fall time of $76 \mu \mathrm{s}$ is observed. When the illumination intensity is increased to $80 \mathrm{~mW}$ (Switch B), the fall time is increased to $89 \mu \mathrm{s}$. This is an increase of $17 \%$ in the switching time

Note that when gap width is increased in the case of the $55 \mathrm{~mW}$ optical illumination intensity (switches A and C) the fall time is reduced by $13 \mu \mathrm{s}(17 \%)$. For the case of the $80 \mathrm{~mW}$ optical illumination intensity (switches B and D) the fall time is reduced by $20 \mu \mathrm{s}(22 \%)$. 


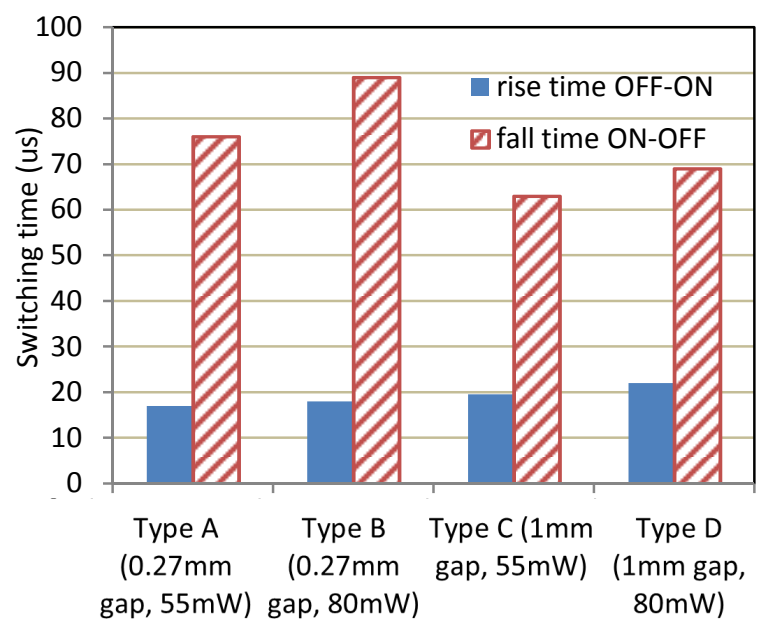

Fig. 7. Rise and fall times for switches which have either a $0.27 \mathrm{~mm}$ or $1 \mathrm{~mm}$ gap. Two illumination intensities are investigated, $55 \mathrm{~mW}$ and $80 \mathrm{~mW}$.

\section{B. Passivation}

In order to quantify the effect passivation has on switching time, three samples with varying degrees of passivation are investigated as described in Table I. In this section switch variations $\mathrm{B}, \mathrm{E}$ and $\mathrm{F}$ are investigated. The level of passivation is quantified in terms of carrier lifetime. Measurements were taken using the Quasi-steady state photo conductance method. Quoted values are for wafer samples prior to dicing. The results for rise and fall times for each switch are presented in Fig. 8. In this scenario, the silicon die is illuminated with a light intensity of $80 \mathrm{~mW}$ and the gap size is kept at $0.27 \mathrm{~mm}$.

The type of silicon used in Switch B has been processed to contain the least density of traps using precise passivation techniques and has a measured wafer carrier lifetime of $600 \mu \mathrm{s}$. Its fall time is $89 \mu \mathrm{s}$. The basic passivated silicon used in Switch $\mathrm{E}$ has undergone a less expensive, less rigorous passivation process when compared to Switch B and has a

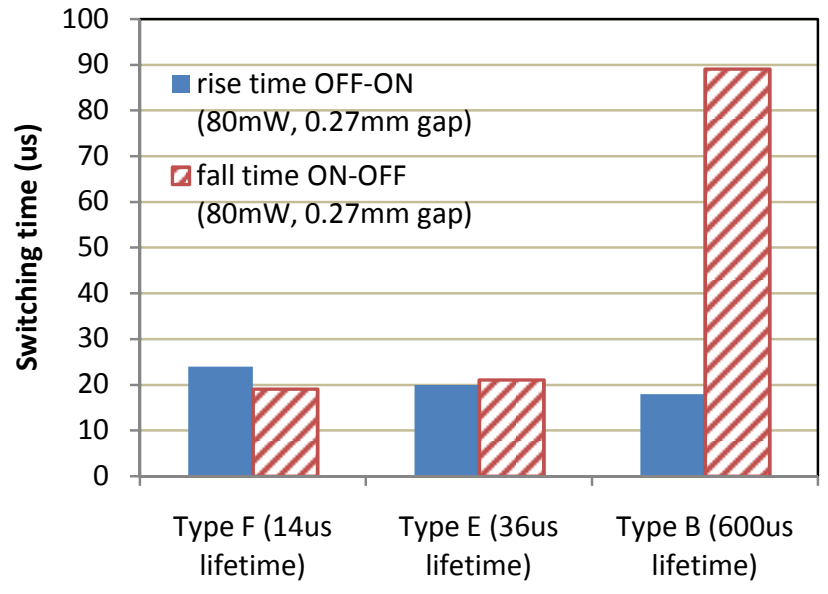

Fig. 8. Rise and fall times for switches incorporating silicon which has been passivated in different ways and under illumination intensity of $80 \mathrm{~mW}$.

measured carrier lifetime of $36 \mu \mathrm{s}$ and a fall time of $21 \mu \mathrm{s}$. Switch $\mathrm{F}$ is made from unpassivated silicon (carrier lifetime $14 \mu \mathrm{s})$ and has a fall time of $19 \mu \mathrm{s}$.

The fall time for the high carrier lifetime silicon (Switch B) is three times longer when compared with switches $F$ and E. Since passivation improves the quality of the silicon by eliminating defects at the surface, the electrons and holes take longer to recombine, leading to a longer switch fall time. If the free carriers are not swept out of the system, then switch fall time is dictated by natural recombination.

Also of particular note, is the voltage difference between $\mathrm{ON}$ and OFF state $\Delta$ voltage $(\Delta \mathrm{V})$, table II. In the case of passivation, larger $\Delta \mathrm{V}$ also results in a longer fall time of the switch. Since $\Delta \mathrm{V}$ is a direct indication of switch transmission, a reduced fall time can be achieved by using silicon which does not have a long carrier lifetime.

TABLE II

RISE AND FALL TIMES OF THE VARIOUS SWITCH TYPES, INCLUDING ON AND OFF STATE VOLTAGES.

\begin{tabular}{|c|c|c|c|c|c|c|c|c|}
\hline $\begin{array}{l}\text { Switch } \\
\text { Name }\end{array}$ & Short Description * & $\begin{array}{c}\text { ON voltage } \\
(\mathrm{mV})\end{array}$ & $\begin{array}{c}\text { OFF voltage } \\
(\mathrm{mV})\end{array}$ & $\begin{array}{c}\Delta \text { voltage } \\
(\mathrm{mV})\end{array}$ & $\begin{array}{c}\text { Rise } \\
\text { Time } \\
(\mu s)\end{array}$ & $\begin{array}{c}\text { Fall } \\
\text { Time } \\
(\mu s)\end{array}$ & $\begin{array}{c}\text { Rising edge } \\
\Delta \mathrm{V} / \Delta \mathrm{t} \\
(\mathrm{V} / \mathrm{ms})\end{array}$ & $\begin{array}{c}\text { Falling edge } \\
\Delta \mathrm{V} / \Delta \mathrm{t} \\
(\mathrm{V} / \mathrm{ms})\end{array}$ \\
\hline A & $\begin{array}{c}0.27 \mathrm{~mm} \text { gap } \\
55 \mathrm{~mW}, 600 \mathrm{us}\end{array}$ & 42 & 6 & 36 & 17 & 76 & 2.12 & 0.47 \\
\hline $\mathrm{B}$ & $\begin{array}{c}0.27 \mathrm{~mm} \text { gap } \\
80 \mathrm{~mW}, 600 \mathrm{us}\end{array}$ & 50 & 6 & 44 & 18 & 89 & 2.44 & 0.49 \\
\hline $\mathrm{C}$ & $\begin{array}{c}1 \mathrm{~mm} \text { gap } \\
55 \mathrm{~mW}, 600 \mathrm{us}\end{array}$ & 32 & 5 & 27 & 19.5 & 63 & 1.38 & 0.43 \\
\hline $\mathrm{D}$ & $\begin{array}{c}1 \mathrm{~mm} \text { gap } \\
80 \mathrm{~mW}, 600 \mathrm{us}\end{array}$ & 43 & 5 & 38 & 22 & 69 & 1.73 & 0.55 \\
\hline $\mathrm{E}$ & $\begin{array}{l}0.27 \mathrm{~mm} \text { gap } \\
80 \mathrm{~mW}, 36 \mathrm{us}\end{array}$ & 29 & 7 & 22 & 20 & 21 & 1.1 & 0.1 \\
\hline $\mathrm{F}$ & $\begin{array}{l}0.27 \mathrm{~mm} \text { gap } \\
80 \mathrm{~mW}, 14 \mathrm{us}\end{array}$ & 17 & 6.5 & 10.5 & 24 & 19 & 0.44 & 0.55 \\
\hline
\end{tabular}

\footnotetext{
*For a more full description please refer to Table I
} 
In contrast to the differing fall time for the passivated and non-passivated samples, the rise time for the three switches are relatively similar. They are $24 \mu \mathrm{s}, 20 \mu \mathrm{s}$ and $18 \mu \mathrm{s}$ for Switch F, E and B respectively. In the case of rise time, as $\Delta \mathrm{V}$ increases rise time reduces - the opposite to what is observed for the fall time. The focus of this paper is to concentrate on rise and fall time with regards to illumination intensity, switch geometry and silicon quality. Hence the rate of change of voltage with respect to time $(\Delta \mathrm{V} / \Delta \mathrm{t})$ for the rising and falling edges may be a more suitable parameter for comparing between switches. This eliminates the effect that a large $\Delta \mathrm{V}$ will have on switching rise and fall times.

\section{ON-OFF State Voltage Difference}

It is clear that the difference in transmitted RF signal amplitude between the $\mathrm{ON}$ and OFF state (referred to as $\Delta$ voltage) has a large bearing on switching time. As is expected those switches with larger ON-OFF voltage differences have longer switch OFF times, however there is less variation in switch ON time. In order to study this further the rising and falling edge gradient for all six switch types have been calculated using the equation (1):

$$
\text { Rising (falling)edge gradient }=\frac{\Delta \text { voltage }}{\text { Rise }(\text { fall }) \text { time }}
$$

The results are shown in Table II. Hence, the gradient of the rising and falling edges of each switch are independent of the ON-OFF voltage values. This makes it plainly clear that the dependence is also linked to other factors such as switch geometry, light intensity and passivation quality.

First investigating the light intensity aspect, in the case of the $0.27 \mathrm{~mm}$ switch with $600 \mu$ s lifetime (switch A and B), there is a $14 \%$ increase in rising edge gradient between $55 \mathrm{~mW}$ and $80 \mathrm{~mW}$ light intensity. For switch $\mathrm{C}$ and $\mathrm{D}$, the $1 \mathrm{~mm}$ geometry switch, the corresponding increase is $20 \%$. Increase in light intensity leads to a steeper rising edge gradient. Increasing the light intensity increases the rate at which photons enter the silicon. This corresponds to faster generation of free electrons, which is finally observed as a decrease in the rise time.

In terms of geometry of the gap, the gradient of the line decreases as gap width increases. Comparing switch type A and $\mathrm{C}$ there is a $35 \%$ reduction in the rising edge gradient. For the higher illumination intensity of $80 \mathrm{~mW}$ the difference in rising edge gradient of switch type B and D is $29 \%$. Maximum coupling between the transmission line and the silicon die is achieved faster for the smaller gap geometry. This is likely because the free electrons created in the silicon diffuse within the die. More of the bottom surface of the die is in contact with the transmission lines in the $0.27 \mathrm{~mm}$ gap geometry (switches A and B), hence rising edge gradient is increased.

For the three different carrier lifetimes of silicon, there is also marked variation in the rising edge gradient. For the highest carrier lifetime of $600 \mu$ s (switch B) the gradient is $2.44 \mathrm{~V} / \mathrm{ms}$. For switch $\mathrm{E}$ which corresponds to the carrier lifetime of $36 \mu$ s the rising edge gradient is $1.1 \mathrm{~V} / \mathrm{ms}$. Switch $\mathrm{F}$ (lifetime of $14 \mu \mathrm{s}$ ) exhibits a rising edge gradient of just $0.44 \mathrm{~V} / \mathrm{ms}$.

As the silicon carrier lifetime increases, the gradient of the rising edge also increases - switch rise time is reduced.
The probable cause relates to the fact that trap density is reduced in samples A and B due to high quality passivation. Hence, recombination of carriers in the silicon due to the Shockley-Read-Hall recombination mechanism is less likely to occur.

Falling edge gradient is similar for all the switches if the result for switch $\mathrm{E}$ is disregarded. This suggests that the fall time is largely dictated by the difference in voltage between OFF and ON state, and not the geometry or light intensity of the switch. Once illumination is removed, the illumination intensity has no effect on the rate of recombination. Hence rate of change of voltage for the falling edge does not vary between switches to such an extent as for the rising edge.

\section{CONCLUSION}

The rise and fall time has been presented for six different variations of a photoconductive switch for an input RF signal of $2 \mathrm{GHz}$. The effect of illumination intensity has been reported for the switch incorporating silicon which has a high level of passivation. Generally, a higher illumination intensity results in a steeper rising edge gradient. It also has the effect of increasing switch transmission. The higher OFF-ON ratio created by this scenario means fall time increases.

The use of passivation reduces rise time of the switch. However silicon which has an increased carrier lifetime due to the passivation process has a corresponding higher transmission and longer switch fall time. Increasing the transmission line gap width increases the rise time of the switch, correspondingly the fall time of the switch is reduced.

Should fast switching speeds be required for a particular application the choice of fabrication method and geometry of the switch design should be considered. For such switching time critical applications, it has also been demonstrated that the designer should implement the minimum ON-OFF transmission needed to ensure the fastest possible switching speeds.

In contrast to photoconductive switches, PIN diodes and MEMS switches generally do not have the ability to control the ON voltage, or transmission, in the ON state. Hence photoconductive switches are highly configurable in terms of controlling both transmission and switching speed - both of which are application dependent.

\section{FUTURE WORK}

This initial work presents preliminary data for different passivation qualities and optical control intensities. A more detailed analysis of switching time and insertion loss will be investigated based on further criteria such as wavelength of illumination source and frequency of operation.

\section{REFERENCES}

[1] A. M. Yadav, C. J. Panagamuwa and R. D. Seager, "Investigation of a plug hole shaped frequency and pattern reconfigurable antenna using photo-conductive microwave switches," 41st European Microwave Conference (EuMC), pp. 878-881, Oct. 2011

[2] D.Draskovic, J. R. O Fernandez, and C. Briso-Rodriguez, "A high isolation series-shunt photoconductive switching circuit" International Topical Meeting on Microwave Photonics (MWP), pp. 224-227, 2012

[3] C. J. Panagamuwa, A. Chauraya, and J. C. Vardaxoglou, "Frequency and beam reconfigurable antenna using photoconducting switches," IEEE Trans. Antennas Propagatation, vol. 54, no.2, pp. 449-454, 2006 
[4] E. K. Kowalczuk, C. J. Panagamuwa, R. D. Seager, and J. C. Vardaxoglou, "Characterising the linearity of an optically controlled photoconductive microwave switch," Loughborough Antennas and Propagation Conference (LAPC), Nov. 2010

[5] A. Karabegovic, R. M. O'Connell, and W. C. Nunnally, "Photoconductive switch design for microwave applications," IEEE Trans. Dielectrics and Electrical Insulation, vol. 16, No. 4, 2009

[6] J. R. Flemish, and R. L. Haupt, "Optimisation of a photonically controlled microwave switch and attenuator," IEEE transactions on microwave theory and tecniques, vol. 58, No. 10, 2010.
[7] Y. Tawk, S. Hemmady, C. G. Christodoulou, and G. Balakrishnan, "Measuring the transition switching speed of a semiconductor-based photoconductive switch using RF techniques," IEEE international Symposium on Antennas and Propagation, pp. 972-975, July 2011

[8] OSRAM LED datasheet "SFH 4232,IR LED Emitter,850nm 120deg “ available online http://uk.rs-online.com/web/p/ir-leds/6811244/ last accessed June 2013

[9] E. K. Kowalczuk, R. D. Seager, C. J. Panagamuwa, K. Bass and J. C. Vardaxoglou, "Optimising the performance of an optically controlled photoconductive microwave switch," Loughborough Antennas and Propagation Conference (LAPC), Nov. 2012 